Public Abstract

First Name:Farah

Middle Name:Mohammad

Last Name:Alnaqqash

Adviser's First Name:Sarah

Adviser's Last Name:Orton

Co-Adviser's First Name:

Co-Adviser's Last Name:

Graduation Term:SP 2017

Department:Civil Engineering

Degree:MS

\title{
Title:EVALUATION OF POST PUNCHING CAPACITY OF FLAT PLATES UNDER PROGRESSIVE COLLAPSE
}

This research investigates the post-punching resistance of flat-plate buildings without continuous bottom reinforcement. An overview on both the historical development of the analytical theories of punching mechanisms and post punching mechanisms as well as the evaluation of post punching capacity of slabcolumn connections will be included. The main aim of this work is to develop an analytical method to reasonably and practically evaluate the post punching response of flat-plates buildings designed without integrity reinforcement. $\mathrm{ACl}$ code provisions have required continuous integrity reinforcement since 1989. However, it is often considered for older flat-plate buildings designed prior to 1989, that contribution of the top flexural reinforcement is limited or even negligible in post-punching. Based on the experimental observations, along with the findings of the literature experimental tests, the model is evolved to estimate the post-punching resistance due to the top reinforcement. In addition, the effect of two parameters, anchorage and lateral restraint conditions, will be incorporated. The proposed model was found to accurately estimate the post punching capacity of the experimentally tested specimens provided by Peng et. al. 2016. The average ratio of the experimental peak deflection to the estimated peak deflection is 1.176. The average ratio of the experimental peak post-punching strength to the estimated peak post punching strength is 0.998 . 